\title{
Longitudinal trajectories of comorbid PTSD and depression symptoms among U.S. service members and veterans
}

\author{
Richard F. Armenta ${ }^{1,2,3^{*}} \mathbb{D}$, Kristen H. Walter ${ }^{2,4}$, Toni Rose Geronimo-Hara ${ }^{2,3}$, Ben Porter ${ }^{2,3}$, Valerie A. Stander ${ }^{3}$, \\ Cynthia A. LeardMann ${ }^{2,3}$ and for the Millennium Cohort Study Team
}

\begin{abstract}
Background: Posttraumatic stress disorder (PTSD) often co-occurs with other psychiatric disorders, particularly major depressive disorder (MDD). The current study examined longitudinal trajectories of PTSD and MDD symptoms among service members and veterans with comorbid PTSD/MDD.

Methods: Eligible participants $(n=1704)$ for the Millennium Cohort Study included those who screened positive at baseline for both PTSD (PTSD Checklist-Civilian Version) and MDD (Patient Health Questionnaire). Between 2001 and 2016, participants completed a baseline assessment and up to 4 follow-up assessments approximately every 3 years. Mixture modeling simultaneously determined trajectories of comorbid PTSD and MDD symptoms. Multinomial regression determined factors associated with latent class membership.

Results: Four distinct classes (chronic, relapse, gradual recovery, and rapid recovery) described symptom trajectories of PTSD/MDD. Membership in the chronic class was associated with older age, service branch, deployment with combat, anxiety, physical assault, disabling injury/illness, bodily pain, high levels of somatic symptoms, and less social support.

Conclusions: Comorbid PTSD/MDD symptoms tend to move in tandem, and, although the largest class remitted symptoms, almost $25 \%$ of participants reported chronic comorbid symptoms across all time points. Results highlight the need to assess comorbid conditions in the context of PTSD. Future research should further evaluate the chronicity of comorbid symptoms over time.
\end{abstract}

Keywords: Comorbidity, Posttraumatic stress disorder, Major depressive disorder, Military personnel, Veterans

\section{Background}

Posttraumatic stress disorder (PTSD) is a psychiatric disorder that can result from exposure to a traumatic event in both military and civilian populations [1]. PTSD is especially likely to co-occur with other psychiatric disorders [2], referred to as comorbidity. PTSD is more commonly accompanied by other psychiatric disorders than existing alone [3], including in US active duty service members $[4,5]$. Among the psychiatric disorders, major depressive disorder (MDD) is highly comorbid with PTSD (52\% [6];) and the disorder

\footnotetext{
* Correspondence: rarmenta@csusm.edu

'Department of Kinesiology, College of Education, Health, and Human

Services, California State University, San Marcos, CA, USA

2Leidos, 11951 Freedom Drive, Reston, VA 20190, USA

Full list of author information is available at the end of the article
}

most frequently comorbid with PTSD among active duty service members $[4,7]$. PTSD and MDD comorbidity is associated with greater negative sequelae for individuals with both disorders in comparison to those with either disorder alone, including reduced perceived social support [8], poorer occupational and social functioning [9], greater health care utilization [10-13], and a significantly elevated risk for persistent PTSD symptoms and suicide [14-17].

Despite the prevalence of comorbid PTSD and MDD, and the deleterious outcomes related to this comorbidity, little is known about how these symptoms fluctuate concurrently over time and what factors are associated with comorbid symptom trajectories. A growing literature has detailed heterogeneous trajectories of PTSD over time following traumatic exposure [18]. Generally,

(c) The Author(s). 2019 Open Access This article is distributed under the terms of the Creative Commons Attribution 4.0 International License (http://creativecommons.org/licenses/by/4.0/), which permits unrestricted use, distribution, and reproduction in any medium, provided you give appropriate credit to the original author(s) and the source, provide a link to the Creative Commons license, and indicate if changes were made. The Creative Commons Public Domain Dedication waiver (http://creativecommons.org/publicdomain/zero/1.0/) applies to the data made available in this article, unless otherwise stated. 
these studies have found four separate trajectories describing resilience, chronicity, recovery, and delayed onset. Resilience is the most common trajectory, particularly among military members. Previous studies have found fewer than $20 \%$ of service members categorized in all other trajectories combined [19-21]. Results from these previous studies, which include such a large proportion of resilient individuals, may mask important heterogeneity among individuals with high symptomatology. For example, in these studies, typically only one trajectory includes individuals with high symptomology at baseline. Therefore, limited information is available about potential heterogeneity among clinical populations. Specifically, studies have not directly addressed symptom trajectories among individuals with comorbid PTSD and MDD [22-25]. Thus, given the high prevalence and co-occurrence of MDD among individuals with PTSD, and the greater impairment associated with comorbid PTSD and MDD, it is important to understand prognostic symptom patterns among this subgroup. The current study aimed to fill this knowledge gap by identifying comorbid symptom trajectory classes among a representative sample of service members and veterans with probable comorbid PTSD and MDD. A second objective of this study is to determine factors predictive of symptom trajectories to be able to identify those who may have a more persistent course of symptoms potentially warranting further intervention.

\section{Methods}

\section{Study population and data sources}

Launched in 2001, the Millennium Cohort Study is the largest longitudinal study of military personnel and veterans $[26,27]$. Enrolled in phases, service members are recruited from all service branches and components (i.e., active duty, Reserves, National Guard) to examine the long-term health of military service. Following enrollment, participants are requested to complete selfadministered surveys (online or paper) approximately every 3 years. The Millennium Cohort survey assesses physical, behavioral, and mental health, as well as military and non-military life experiences. Detailed descriptions of the methods of this study have been published elsewhere [26-28].

The current study included Millennium Cohort participants who enrolled in 2001, 2004, or 2007. Eligible participants must have screened positive for both PTSD and MDD at baseline and completed at least 2 additional follow-up questionnaires, resulting in a final study population of 1704 participants. This study was approved by the institutional review board at the Naval Health Research Center, and all participants provided voluntary, written informed consent.

\section{Measures}

\section{PTSD and MDD}

Based on eligibility criteria, participants must have screened positive for PTSD and MDD at baseline. PTSD was assessed with the PTSD Checklist-Civilian Version (PCL-C) [29]. PTSD screening criteria were consistent with diagnostic criteria of the Diagnostic and Statistical Manual of Mental Disorders, Fourth Edition, Text Revision (DSM-IV-TR) [30] of endorsing "Moderately" or higher on at least 1 intrusion item, 2 hyperarousal items, and 3 avoidance items. This DSM-IV-TR criterion for scoring the PCL-C has been shown to correspond to a total cutoff of 44 in military personnel, a sufficiently high threshold for estimating prevalence in a population based study [31, 32]. MDD was measured using the 8item depression scale from the Patient Health Questionnaire (PHQ-8) [33], consistent with the DSM-IV-TR criteria of endorsing at least 5 items as "More than half the days" or higher, in which 1 of the symptoms was anhedonia or depressed mood. Previous studies have found substantial agreement between the PHQ-8 and the PHQ-9 [34].

The outcome of interest in this study was comorbid PTSD and MDD symptom severity, where higher scores indicated increasing morbidity. At each follow-up, PTSD symptom severity was assessed and calculated as the sum of the 17 PTSD Checklist-Civilian Version items, with scores ranging from 17 to 85 . MDD symptom severity was also evaluated at each time point and scored as the sum of the PHQ- 8 items, which ranged from 0 to 24 . Higher scores are suggestive of higher symptom severity for both measures.

\section{Covariates}

Covariates were included based on factors associated with PTSD and MDD identified in prior research [17, 35-38].

\section{Demographic and military characteristics}

Age, sex, race/ethnicity, service branch, service component, and pay grade were obtained from personnel records maintained by the Defense Manpower Data Center upon study enrollment (baseline visit). Marital status and education were self-reported at baseline.

\section{Deployment and combat deployment}

Deployment history prior to baseline was assessed using electronic deployment data, obtained from the Defense Manpower Data Center, in combination with selfreported combat experience measured at baseline. Participants were categorized as deployed, deployed without combat, or deployed with combat. Those who deployed were considered to have experienced combat if they reported personal exposure to at least 1 of the following: 
witnessing death, physical abuse, dead and/or decomposing bodies, maimed soldiers or civilians, or prisoners of war or refugees.

\section{Life events}

Childhood trauma of physical abuse, sexual abuse, verbal abuse, and neglect before the age of 18 was assessed on the 2016 survey using items from the Juvenile Victimization Questionnaire [39]. Each experience was categorized as happening never, once or more, or prefer not to answer. Sexual assault, physical assault, and disabling injury/illness were each assessed as individual binary covariates using 1 item each. Other life events, including sexual harassment, divorce, and financial stress, were summed and combined into a single categorical variable (range, 0-3) [17]. These stressful life events are broadly based on a modified version of the Social Readjustment Rating Scale-Revised [40] with items that were considered criterion A kept as separate items and those items not considered criterion A collapsed into one variable as demonstrated by others [40].

\section{Behavioral characteristics, mental health, and comorbid conditions}

Behavioral characteristics and mental health conditions were based on self-reported data at baseline. Body mass index, calculated from self-reported height and weight, was classified as healthy $\left(<25.0 \mathrm{~kg} / \mathrm{m}^{2}\right)$, overweight $\left(25.0-29.9 \mathrm{~kg} / \mathrm{m}^{2}\right)$, and obese $\left(>29.9 \mathrm{~kg} / \mathrm{m}^{2}\right)$. Smoking status was categorized as never smokers (smoked less than 100 cigarettes), former smokers (smoked at least 100 cigarettes but quit successfully), and current smokers (smoked at least 100 cigarettes but did not report quitting). Alcohol problems were identified as an affirmative response to any of the 5 problematic drinking behaviors based on the related Patient Health Questionnaire (PHQ) alcohol module (e.g., "drank alcohol even though a doctor suggested that you stop drinking because of a problem with your health" or "drove a car after having several drinks or after drinking too much") [41]. Sleep duration was determined by self-reported hours of sleep on average each night. Social support was based on a single item: "During the last 4 weeks, how much have you been bothered by having no one to turn to when you have a problem," with 3 response options: "not bothered," "bothered a little," and "bothered a lot" [17].

Using the standardized PHQ scoring mechanisms, other anxiety syndrome was assessed at baseline using 6 generalized anxiety items [41]. Bodily pain was assessed using the corresponding profile from the Medical Outcomes Study ShortForm 36-item Survey for Veterans [42]. Scores ranged from 0 to 100 with a higher score indicating more bodily pain and were rescaled on a 0 to 4 scale (where 4 represented highest level of pain) to aid interpretability. Somatic symptoms were identified using the PHQ-15. Items were summed (range, $0-30 ; \alpha=0.82$ ) [43] and collapsed into the 3 standard categories (0-9, $10-14$, and $\geq 15$ ) [44].

\section{Statistical analysis}

Mixture modeling was used to develop trajectory classes that simultaneously captured non-linear trajectories of PTSD and MDD symptoms. This means that every estimated class had 2 trajectories associated with it; 1 for PTSD and 1 for MDD. Mean PTSD and MDD symptoms were allowed to vary across classes. Mixture modeling estimation used a robust maximum likelihood estimator, which uses full information maximum likelihood to account for missing outcome data and estimate values based on all available data [45]. Unadjusted models with 2 to 7 latent classes were examined to determine the ideal number of classes for the final model. The optimal number of classes was selected using a combination of Bayesian information criterion, LoMendell-Rubin adjusted likelihood ratio test, bootstrap likelihood ratio test, and interpretability of trajectory classes [46, 47]. Additionally, all trajectory classes were required to have at least $2 \%$ of the total study population to prevent unstable trajectory classes. Covariates predicting latent classes were entered directly into the mixture model to determine an adjusted model. Missing covariate data were assigned a special missing code to prevent the listwise deletion of incomplete observations. In addition to demonstrating associations with mental health trajectories, similarity between the adjusted and unadjusted models indicate model stability. To ensure that related PTSD and MDD trajectories were not a result of the overlapping items on the two scales, we ran a sensitivity analysis that removed the overlapping items before scoring (i.e., items on sleep, loss of interest, and trouble concentrating). The scales with removed items were rescored and mixture modeling was conducting following the same methods described above. Multicollinearity was assessed using variance inflation factors (VIF) with a VIF $>4$ indicating collinearity between covariates; no covariates were above this threshold. All data manipulation was performed using SAS, version 9.4 (SAS Institute Inc., Cary, North Carolina), and all mixture models were performed using Mplus, version 8.0.

\section{Results}

Of the 1704 study participants, the majority were male (60.9\%), non-Hispanic white (71.3\%), college educated (74.3\%), in the Army (57.9\%), active duty (66.9\%), and enlisted (93.4\%) with a mean age of 29.1 years (standard deviation, 8.6). A total of $30.3 \%$ of participants deployed 
before their baseline assessment; of those, $85.5 \%$ selfreported combat experience.

Table 1 shows model fit and selection criteria for 2 to 7 latent classes of comorbid PTSD/MDD, as well as unadjusted percentages of participants in each class. A 4class solution was selected to represent trajectories of probable comorbid PTSD/MDD using a combination of criteria, including a low Bayesian information criterion, high entropy, significant Lo-Mendell-Rubin adjusted likelihood ratio test of the 5-class solution did not significantly improve model fit beyond the 4-class model, and interpretability of classes (Table 1). The average posterior probabilities of membership in classes $1,2,3$, and 4 were $0.91,0.97,0.80$, and 0.91 , respectively, indicating distinct classes. Class 1, which included $31.1 \%$ of participants, was defined as the rapid recovery class. Participants in this class remitted symptoms by the first follow-up and remained at a low level of symptom severity for both conditions throughout the study period. Class 2, which included $26.1 \%$ of participants, was considered chronic. The chronic class showed the highest level of symptom severity for both PTSD and MDD throughout the study period. Class 3, which included $24.5 \%$ of participants, was categorized as relapse. Participants in the relapse class had a lower level of symptom severity for both PTSD and MDD at their first followup, but their symptoms steadily worsened again over the remainder of the study period. Class 4 , the smallest class with $18.3 \%$ of participants, was classified as the gradual recovery class. For those in the gradual recovery class, both PTSD and MDD symptoms steadily remitted throughout the study period.

Figure 1 shows the joint trajectories of comorbid PTSD/MDD in the fully adjusted model. Class trajectories did not noticeably change after adjusting for covariates in the model indicating stability of the 4-class solution [46]. Further, in the sensitivity analysis that removed overlapping items from the scale, the trajectories were nearly identical to the original trajectories with no items removed (Additional file 1: Figure S1). In adjusted models, participants in the chronic class had higher odds of being older, Hispanic, less educated, and deployed with combat compared with those in the rapid recovery class (Table 2). They also had higher odds of having anxiety, inadequate social support, having been physically assaulted, a disabling injury or illness, and elevated bodily pain or somatic symptoms. Membership in the relapse class was associated with higher odds of combat deployment, obesity, and childhood physical abuse compared with the rapid recovery class in adjusted models. Finally, in adjusted models, those in the gradual recovery class had higher odds of having anxiety, inadequate social support, and a disabling injury or illness; in addition, they had higher odds of sleeping $>9 \mathrm{~h}$ per night compared with 7 to $9 \mathrm{~h}$ a night compared with those in the rapid recovery class(Table 2 ).

\section{Discussion}

This current study is among the first, to our knowledge, to longitudinally examine the patterns of PTSD and MDD symptoms across approximately 15 years of follow-up among those with probable comorbid PTSD/ MDD at baseline. Four distinct classes of probable comorbid PTSD/MDD were identified among service members and veterans, which illustrate how these comorbid symptoms move in relation to one another over time. The 4 identified classes of PTSD/MDD are consistent with other research that examined trajectories of PTSD and depression separately [23, 48, 49], but

Table 1 Model Fit and Selection Criteria for 2 to 7 Latent Classes for Comorbid Posttraumatic Stress Disorder and Major Depressive Disorder

\begin{tabular}{|c|c|c|c|c|c|c|}
\hline & 2 classes & 3 classes & 4 classes $^{a}$ & 5 classes & 6 classes & 7 classes \\
\hline $\mathrm{BIC}$ & 90,759 & 89,985 & 89,612 & 89,391 & 89,228 & 89,089 \\
\hline$P$ from $L M R$ & $<0.001$ & $<0.001$ & 0.010 & 0.300 & 0.276 & 0.240 \\
\hline$P$ from BLRT & $<0.001$ & $<0.001$ & $<0.001$ & $<0.001$ & $<0.001$ & $<0.001$ \\
\hline Entropy & 0.854 & 0.807 & 0.783 & 0.779 & 0.767 & 0.760 \\
\hline Percentage in class 1 & 52.7 & 38.6 & 31.1 & 30.0 & 26.7 & 24.2 \\
\hline Percentage in class 2 & 47.3 & 35.5 & 26.1 & 23.0 & 22.9 & 16.3 \\
\hline Percentage in class 3 & & 25.9 & 24.5 & 17.3 & 13.4 & 14.5 \\
\hline Percentage in class 4 & & & 18.3 & 15.7 & 13.1 & 12.1 \\
\hline Percentage in class 5 & & & & 14.0 & 12.6 & 12.1 \\
\hline Percentage in class 6 & & & & & 11.4 & 10.9 \\
\hline Percentage in class 7 & & & & & & 9.8 \\
\hline
\end{tabular}

BIC Bayesian information criterion, BLRT bootstrap likelihood ratio test, LMR Lo-Mendell-Rubin adjusted likelihood ratio test

a Selected class solution is bolded 


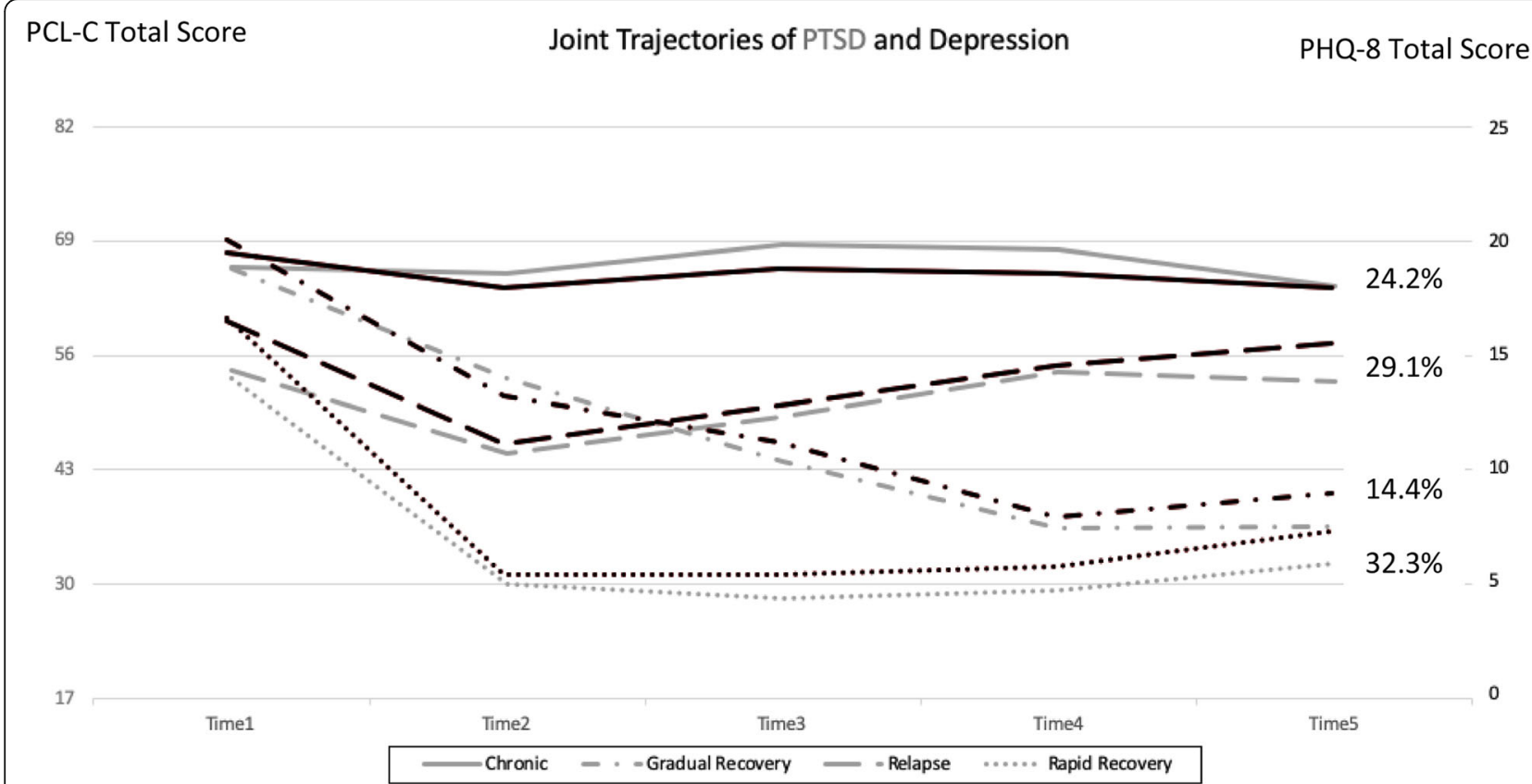

Fig. 1 Joint trajectories of comorbid posttraumatic stress disorder (PTSD) and major depressive disorder (MDD) adjusted for covariates in the model. Black indicates trajectories for MDD and gray indicates trajectories for PTSD. All participants screened positive for comorbid PTSD/MDD at time 1. Each time point is approximately 3 years apart. Abbreviations: PCL-C, PTSD Checklist-Civilian Version; PHQ-8: Patient Health Questionnaire 8-item depression scale. Gray line: PTSD. Black line: MDD

uniquely highlight how the symptoms of these comorbid conditions move in tandem with one another.

The largest of the 4 classes (32.3\%) included participants who remitted symptoms for both PTSD and MDD and remained at a low level of symptoms throughout the study period. Further, $14.4 \%$ of participants gradually remitted symptoms for PTSD and MDD. Participants in these classes had less comorbid health conditions and, on average, were less likely to experience childhood trauma and stressful life events. Alternatively, almost $25 \%$ of participants maintained chronically high levels of comorbid PTSD/MDD symptoms throughout the entire study period. This high level of persistence of symptoms is consistent with previous literature, which indicates that symptoms of PTSD and depression often endure for many years, sometimes decades [50]. Yet, prior findings suggest individuals with comorbid PTSD/MDD are more likely to have persistent symptoms than those with only PTSD or MDD [17]. In a previous study, results showed that service members with PTSD who had comorbid MDD were more likely to have persistent PTSD up to 6 years after initially screening positive [17]. This persistence of symptoms highlights the need to identify effective treatments for those with comorbid PTSD/MDD and better understand factors associated with membership in classes of comorbid PTSD/MDD-particularly those with chronic symptoms. Further, previous PTSD trajectory work has highlighted the benefit of tailoring interventions and treatment for
PTSD based on the specific trajectory patterns of the individual [51, 52]. Specifically, Galantzer et al. 2013 found that early treatment affected symptom remittance for those who were in the slow recovery class, but not for those in a rapid remittance trajectory [51]. Using a more integrative medicine approach that accounts for the whole person and addresses other mental and physical conditions may help reduce symptoms and lead to less comorbidity over time $[53,54]$.

Restriction of the sample to individuals meeting criteria for probable PTSD and MDD precluded the formation of many typical classes (e.g., delayed onset, resilience) found in prior studies [18]. Rather than two trajectories (chronicity and recovery) describing individuals with high symptoms, the current study identified four different trajectories of change among individuals with probable comorbid PTSD/MDD. Additionally, even for trajectories that are similar to those found previously (i.e., chronic and gradual recovery trajectories), the level of symptoms reported in the current study was higher than in prior studies [19-21]. This suggests poorer prognoses of individuals with probable comorbid PTSD/MDD. Even within the rapid recovery trajectory, which is most comparable to resilience trajectories, participants continued to report a moderate level of symptoms across the study period. However, similar to prior studies, the proportion exhibiting this optimal trajectory was most 
Table 2 Adjusted Odds Ratios of Characteristics Associated With Membership in the Chronic, Relapse, and Gradual Recovery Classes Compared With the Rapid Recovery Class $(n=1704)$

\begin{tabular}{|c|c|c|c|c|c|c|c|c|}
\hline \multirow{3}{*}{$\overline{\text { Demographics }}$} & \multirow[t]{2}{*}{$n^{a}$} & \multirow[t]{2}{*}{$\%$} & \multicolumn{2}{|c|}{ Chronic (24.2\%) } & \multicolumn{2}{|c|}{ Relapse (29.1\%) } & \multicolumn{2}{|c|}{ Gradual Recovery (14.4\%) } \\
\hline & & & $\mathrm{aOR}$ & $95 \% \mathrm{Cl}$ & $\mathrm{aOR}$ & $95 \% \mathrm{Cl}$ & $\mathrm{aOR}$ & $95 \% \mathrm{Cl}$ \\
\hline & & & & & & & & \\
\hline \multicolumn{9}{|l|}{ Age $^{\mathrm{b}}$} \\
\hline 10-year increment & \multicolumn{2}{|l|}{$29.1(8.6)$} & 1.67 & $1.21,2.30$ & 1.01 & $0.77,1.31$ & 1.31 & $0.76,2.25$ \\
\hline \multicolumn{9}{|l|}{ Sex } \\
\hline Male & 1038 & 60.9 & \multicolumn{2}{|c|}{ Referent } & \multicolumn{2}{|c|}{ Referent } & \multicolumn{2}{|c|}{ Referent } \\
\hline Female & 666 & 39.1 & 0.83 & $0.51,1.33$ & 0.93 & $0.63,1.39$ & 1.14 & $0.57,2.25$ \\
\hline \multicolumn{9}{|l|}{ Race/ethnicity } \\
\hline Non-Hispanic white & 1215 & 71.3 & \multicolumn{2}{|c|}{ Referent } & \multicolumn{2}{|c|}{ Referent } & \multicolumn{2}{|c|}{ Referent } \\
\hline Non-Hispanic black & 210 & 12.3 & 1.51 & $0.85,2.68$ & 1.32 & $0.79,2.20$ & 1.63 & $0.72,3.65$ \\
\hline Hispanic & 161 & 9.5 & 2.21 & $1.16,4.16$ & 0.76 & $0.41,1.40$ & 2.06 & $0.60,7.00$ \\
\hline Other & 118 & 6.9 & 1.38 & $0.66,2.89$ & 0.78 & $0.38,1.61$ & 0.67 & $0.08,5.67$ \\
\hline \multicolumn{9}{|l|}{ Marital status } \\
\hline Single or never married & 624 & 36.6 & \multicolumn{2}{|c|}{ Referent } & \multicolumn{2}{|c|}{ Referent } & \multicolumn{2}{|c|}{ Referent } \\
\hline Currently married & 744 & 43.7 & 0.90 & $0.57,1.42$ & 1.07 & $0.71,1.61$ & 0.89 & $0.48,1.63$ \\
\hline Widowed, divorced, or separated & 336 & 19.7 & 1.09 & $0.60,1.97$ & 1.45 & $0.83,2.54$ & 0.81 & $0.33,1.99$ \\
\hline \multicolumn{9}{|l|}{ Education } \\
\hline Bachelor's degree or higher & 256 & 15.0 & \multicolumn{2}{|c|}{ Referent } & \multicolumn{2}{|c|}{ Referent } & Refere & \\
\hline Some college & 1011 & 59.3 & 2.01 & $0.97,4.14$ & 1.14 & $0.66,1.96$ & 1.97 & $0.32,11.96$ \\
\hline High school or less & 436 & 25.6 & 2.62 & $1.19,5.73$ & 0.94 & $0.51,1.73$ & 2.05 & $0.30,13.76$ \\
\hline Military characteristics & & & & & & & & \\
\hline Service branch & & & & & & & & \\
\hline Army & 987 & 57.9 & Refere & & Refere & & Refere & \\
\hline Navy, Coast Guard & 281 & 16.5 & 0.49 & $0.26,0.94$ & 0.69 & $0.43,1.10$ & 1.76 & $0.70,4.39$ \\
\hline Marine Corps & 191 & 11.2 & 1.18 & $0.65,2.13$ & 0.87 & $0.48,1.56$ & 1.04 & $0.49,2.18$ \\
\hline Air Force & 245 & 14.4 & 0.59 & $0.30,1.15$ & 0.74 & $0.45,1.22$ & 1.00 & $0.46,2.16$ \\
\hline Service Component & & & & & & & & \\
\hline Active duty & 1140 & 66.9 & Refere & & Refere & & Refere & \\
\hline Reserve, National Guard & 564 & 33.1 & 0.90 & $0.59,1.35$ & 0.70 & $0.48,1.02$ & 0.91 & $0.50,1.67$ \\
\hline Pay grade & & & & & & & & \\
\hline Officer & 112 & 6.6 & Refere & & Refere & & Refere & \\
\hline Enlisted & 1592 & 93.4 & 0.90 & $0.33,2.42$ & 1.91 & $0.82,4.40$ & 0.73 & $0.18,2.91$ \\
\hline Deployment/Combat ${ }^{c}$ & & & & & & & & \\
\hline None & 1186 & 69.6 & Refere & & Refere & & Refere & \\
\hline Deployed, no combat & 75 & 4.4 & 1.08 & $0.41,2.84$ & 0.72 & $0.34,1.49$ & 1.18 & $0.44,3.15$ \\
\hline Deployed with combat & 442 & 25.9 & 4.28 & $2.58,7.07$ & 1.63 & $1.05,2.52$ & 1.75 & $0.89,3.44$ \\
\hline Stressful life events & & & & & & & & \\
\hline Childhood physical abuse & & & & & & & & \\
\hline Never & 604 & 35.5 & Refere & & Refere & & Refere & \\
\hline Once or more & 695 & 40.8 & 1.08 & $0.61,1.88$ & 2.42 & $1.49,3.92$ & 0.92 & $0.42,2.01$ \\
\hline Prefer not to answer & 61 & 3.6 & 3.40 & $0.72,15.73$ & 2.11 & $0.55,7.96$ & 4.34 & $0.63,29.6$ \\
\hline Childhood sexual abuse & & & & & & & & \\
\hline Never & 971 & 57.0 & Refere & & Refere & & Refere & \\
\hline
\end{tabular}


Table 2 Adjusted Odds Ratios of Characteristics Associated With Membership in the Chronic, Relapse, and Gradual Recovery Classes Compared With the Rapid Recovery Class ( $n=1704)$ (Continued)

\begin{tabular}{|c|c|c|c|c|c|c|c|c|}
\hline & \multirow[t]{2}{*}{$n^{a}$} & \multirow[t]{2}{*}{$\%$} & \multicolumn{2}{|c|}{ Chronic (24.2\%) } & \multicolumn{2}{|c|}{ Relapse (29.1\%) } & \multicolumn{2}{|c|}{ Gradual Recovery (14.4\%) } \\
\hline & & & $\mathrm{aOR}$ & $95 \% \mathrm{Cl}$ & $\mathrm{aOR}$ & $95 \% \mathrm{Cl}$ & $\mathrm{aOR}$ & $95 \% \mathrm{Cl}$ \\
\hline Once or more & 321 & 18.8 & 1.32 & $0.75,2.30$ & 0.76 & $0.46,1.24$ & 1.28 & $0.50,3.24$ \\
\hline Prefer not to answer & 69 & 4.1 & 0.63 & $0.23,1.71$ & 0.42 & $0.16,1.07$ & 0.65 & $0.14,2.90$ \\
\hline \multicolumn{9}{|l|}{ Childhood verbal abuse } \\
\hline Never & 622 & 36.5 & \multicolumn{2}{|l|}{ Referent } & \multicolumn{2}{|l|}{ Referent } & \multicolumn{2}{|l|}{ Referent } \\
\hline Once or more & 676 & 39.7 & 1.37 & $0.79,2.35$ & 1.38 & $0.83,2.30$ & 1.79 & $0.75,4.25$ \\
\hline Prefer not to answer & 64 & 3.8 & 1.28 & $0.34,4.72$ & 3.44 & $1.09,10.73$ & 0.59 & $0.07,4.55$ \\
\hline \multicolumn{9}{|l|}{ Childhood neglect } \\
\hline Never & 963 & 56.5 & \multicolumn{2}{|l|}{ Referent } & \multicolumn{2}{|l|}{ Referent } & \multicolumn{2}{|l|}{ Referent } \\
\hline Once or more & 346 & 20.3 & 1.57 & $0.87,2.84$ & 1.19 & $0.70,2.03$ & 0.72 & $0.27,1.92$ \\
\hline Prefer not to answer & 56 & 3.3 & 2.50 & $0.59,10.34$ & 0.90 & $0.26,3.02$ & 1.43 & $0.12,16.46$ \\
\hline \multicolumn{9}{|l|}{ Sexual assault } \\
\hline Not endorsed & 1291 & 75.8 & \multicolumn{2}{|l|}{ Referent } & \multicolumn{2}{|l|}{ Referent } & \multicolumn{2}{|l|}{ Referent } \\
\hline Endorsed & 399 & 23.4 & 1.13 & $0.67,1.89$ & 1.02 & $0.63,1.64$ & 0.73 & $0.33,1.58$ \\
\hline \multicolumn{9}{|l|}{ Physical assault } \\
\hline Not endorsed & 1274 & 74.8 & \multicolumn{2}{|l|}{ Referent } & \multicolumn{2}{|l|}{ Referent } & \multicolumn{2}{|l|}{ Referent } \\
\hline Endorsed & 404 & 23.7 & 2.65 & $1.57,4.44$ & 1.39 & $0.85,2.26$ & 2.03 & $0.99,4.14$ \\
\hline \multicolumn{9}{|l|}{ Disabling injury/illness } \\
\hline Not endorsed & 1304 & 76.5 & \multicolumn{2}{|l|}{ Referent } & Referent & & Referent & \\
\hline Endorsed & 375 & 22.0 & 2.26 & $1.30,3.93$ & 1.40 & $0.85,2.27$ & 2.88 & $1.42,5.81$ \\
\hline Other life events ${ }^{d}$ & & & & & & & & \\
\hline Not endorsed & 691 & 40.6 & Referent & & Referent & & Referent & \\
\hline Endorsed & 1000 & 58.7 & 1.08 & $0.67,1.73$ & 0.86 & $0.57,1.30$ & 0.88 & $0.42,1.83$ \\
\hline Behavioral characteristics, mental & and co & bid cor & ions & & & & & \\
\hline Body mass index, $\mathrm{kg} / \mathrm{m}^{2}$ & & & & & & & & \\
\hline Healthy & 617 & 36.2 & Referent & & Referent & & Referent & \\
\hline Overweight & 771 & 45.3 & 1.14 & $0.71,1.82$ & 1.32 & $0.91,1.90$ & 0.77 & $0.32,1.84$ \\
\hline Obese & 293 & 17.2 & 1.24 & $0.67,2.28$ & 1.67 & $1.00,2.76$ & 1.12 & $0.34,3.62$ \\
\hline Smoking status & & & & & & & & \\
\hline Never & 683 & 40.1 & Referent & & Referent & & Referent & \\
\hline Former smoker & 420 & 24.7 & 1.00 & $0.62,1.61$ & 1.20 & $0.81,1.78$ & 1.52 & $0.77,2.98$ \\
\hline Current smoker & 546 & 32.0 & 0.87 & $0.54,1.38$ & 0.92 & $0.60,1.42$ & 1.33 & $0.51,3.42$ \\
\hline Alcohol problems & & & & & & & & \\
\hline None & 1134 & 66.6 & Referent & & Referent & & Referent & \\
\hline Positive for alcohol problems & 549 & 32.2 & 1.51 & $0.99,2.29$ & 0.90 & $0.59,1.36$ & 1.72 & $0.96,3.06$ \\
\hline Sleep duration, hours & & & & & & & & \\
\hline$<5$ & 466 & 27.4 & 1.24 & $0.61,2.48$ & 0.76 & $0.43,1.34$ & 1.76 & $0.60,5.15$ \\
\hline 5 to $<7$ & 835 & 49.0 & 0.86 & $0.45,1.63$ & 1.06 & $0.64,1.73$ & 1.25 & $0.47,3.26$ \\
\hline 7 to $<9$ & 171 & 10.0 & Referent & & Referent & & Referent & \\
\hline$\geq 9$ & 192 & 11.3 & 1.14 & $0.50,2.61$ & 0.72 & $0.35,1.48$ & 2.75 & $1.00,7.48$ \\
\hline Social support ${ }^{\mathrm{e}}$ & & & & & & & & \\
\hline Not bothered & 269 & 15.8 & Referent & & Referent & & Referent & \\
\hline Bothered a little & 506 & 29.7 & 1.92 & $1.06,3.44$ & 0.89 & $0.54,1.48$ & 1.63 & $0.64,4.09$ \\
\hline
\end{tabular}


Table 2 Adjusted Odds Ratios of Characteristics Associated With Membership in the Chronic, Relapse, and Gradual Recovery Classes Compared With the Rapid Recovery Class ( $n=1704)$ (Continued)

\begin{tabular}{|c|c|c|c|c|c|c|c|c|}
\hline & \multirow[t]{2}{*}{$n^{a}$} & \multirow[t]{2}{*}{$\%$} & \multicolumn{2}{|c|}{ Chronic (24.2\%) } & \multicolumn{2}{|c|}{ Relapse (29.1\%) } & \multicolumn{2}{|c|}{ Gradual Recovery (14.4\%) } \\
\hline & & & $\mathrm{aOR}$ & $95 \% \mathrm{Cl}$ & $\mathrm{aOR}$ & $95 \% \mathrm{Cl}$ & $\mathrm{aOR}$ & $95 \% \mathrm{Cl}$ \\
\hline Bothered a lot & 914 & 53.6 & 3.49 & $1.85,6.54$ & 0.83 & $0.42,1.59$ & 4.14 & $1.12,15.14$ \\
\hline \multicolumn{9}{|l|}{ Other anxiety syndrome } \\
\hline Negative & 842 & 49.4 & \multicolumn{2}{|c|}{ Referent } & \multicolumn{2}{|c|}{ Referent } & \multicolumn{2}{|c|}{ Referent } \\
\hline Positive & 812 & 47.7 & 4.27 & $2.42,7.49$ & 0.93 & $0.45,1.91$ & 7.40 & $2.25,24.05$ \\
\hline \multicolumn{9}{|l|}{ Bodily pain ${ }^{\mathrm{b}, \mathrm{f}}$} \\
\hline Continuous (scaled from 0 to 4 ) & \multicolumn{2}{|l|}{$3.52(0.24)$} & 1.86 & $1.44,2.39$ & 1.14 & $0.93,1.39$ & 1.02 & $0.72,1.44$ \\
\hline \multicolumn{9}{|l|}{ Somatic symptoms } \\
\hline $0-9$ & 469 & 27.5 & \multicolumn{2}{|c|}{ Referent } & \multicolumn{2}{|c|}{ Referent } & \multicolumn{2}{|c|}{ Referent } \\
\hline $10-14$ & 611 & 35.9 & 0.82 & $0.49,1.37$ & 1.24 & $0.81,1.90$ & 0.85 & $0.37,1.95$ \\
\hline$\geq 15$ & 613 & 36.0 & 1.84 & $1.08,3.12$ & 1.09 & $0.65,1.80$ & 1.84 & $0.80,4.19$ \\
\hline
\end{tabular}

$a O R$ adjusted odds ratio, $\mathrm{Cl}$ confidence interval; Bolded values are statistically significant with all $p$-values $<0.05$

a Some variables do not add up to 1704 due to missing data. Full information maximum likelihood was performed to account for missing data and estimate values based on all data that was available

${ }^{\mathrm{b}}$ Values are expressed as mean (standard deviation)

c Deployment dates based on data from Defense Manpower Data Center. Combat based on positive endorsement of any of the following combat exposures: witnessing death due to war, disaster, or tragic event; or witnessing instances of physical abuse, dead and/or decomposing bodies, maimed soldiers or civilians, or prisoners of war or refugees

${ }^{\mathrm{d}}$ Endorsement of any of the following stressful life events: divorce, finances, or sexual harassment

e Measured based on Patient Health Questionnaire question, "In the last 4 weeks, how much have you been bothered by having no one to turn to when you have a problem?"

${ }^{\mathrm{f}}$ Higher score indicates more bodily pain

prevalent, however, the prevalence (32.3\%) was much lower than those exhibiting resilience in prior investigations (80-90\%) among those with and without mental health symptoms.

A number of physical, psychosocial, and life experience factors were associated with a chronic course of probable comorbid PTSD/MDD symptoms. In terms of physical factors, those with more bodily pain and/or somatic symptoms were more likely to have chronic symptoms of PTSD/MDD. Previous research indicates that both PTSD and depression affect chronic pain. Comorbid physical symptoms at baseline are strongly associated with newonset and persistence of PTSD $[17,55,56]$. These physical factors are modifiable through multidisciplinary treatment and care.

The psychosocial factors associated with higher odds of membership in the chronic PTSD/MDD class were anxiety and social support. Those with anxiety were more likely to have chronic symptoms compared with those who recovered rapidly. This highlights that many people suffer from multiple overlapping mental health conditions that may impact treatment and long-term symptoms. Further, those who reported being bothered either "a little" or "a lot" by not having enough social support also had higher odds of membership in the chronic comorbid PTSD/MDD trajectory. This finding is consistent with previous literature on the role of social support in new-onset PTSD and depression $[57,58]$ as well as persistent symptoms for PTSD [17]. Given this, it is crucial that individuals receive support during their time in service and during and after their transition out of service. Command leaders should also emphasize the need for and importance of social support. Together, these findings further highlight the interwoven nature of physical and mental health and point to the need to screen for co-occurring psychological and physical conditions in order to identify the best ways to address chronicity of comorbid PTSD/MDD symptoms among service members and veterans.

In addition to physical and psychosocial factors, stressful life events/experiences also predicted elevated probable comorbid PTSD/MDD symptoms over time. Specifically, combat experiences, disabling injury/illness, physical assault, and childhood trauma were associated with comorbid PTSD/MDD. Consistent with previous literature, deployment with combat was associated with elevated symptoms over time. Prior evidence clearly shows that combat deployment is associated with newonset PTSD [59] and depression [60], and with persistent PTSD symptoms among military service members and veterans [17]. Those with a disabling illness/injury and who had experienced physical assault were more likely to have chronic symptoms compared with those who recovered rapidly. Experiencing childhood trauma also significantly increases risk for development of depression and PTSD beyond the role of combat among military service members [36, 61]. Childhood trauma was associated with higher odds of membership in the 
chronic and relapse trajectories in this study. However, once adjusting for other items, including combat, the association between childhood trauma and comorbid symptoms were attenuated and only remained significant with respect to the relapse trajectory. This indicates that other factors, such as combat and more recent life events, may be more directly associated with elevated symptoms of PTSD/MDD. Although life events are not modifiable, responses to these experiences are adaptable and programs should focus on proper support and treatment for combat- and life-related factors that may impact chronic symptoms.

\section{Limitations and strengths}

Results from this study should be interpreted with several limitations in mind. The Millennium Cohort Study sample may not fully reflect the population of military service members and veterans. However, previous studies have found the cohort to be highly representative of service members and veterans overall $[62,63]$. The relatively long 3-year follow-up period between assessments may not fully capture short-term fluctuations in symptoms for PTSD or MDD. However, given the high number of participants who maintained a high level of symptoms over time, and consistency of symptoms throughout the study period, we might not expect to find significant changes on average in PTSD or MDD symptoms over a shorter period of time. We were not able to fully assess differences in trajectories between active duty, Reservist/National Guardsmen, and veterans given changes in status over time. Given this, future studies should explore differences in trajectories between these groups. The self-reported survey data used for analysis may be subject to both recall and reporting bias that could affect the findings. Furthermore, the PTSD Checklist-Civilian Version and PHQ-8 are screening tools for PTSD and MDD, respectively, and are not diagnostic of either condition. Both tools, however, have demonstrated high validity in military and veteran samples, and the items map onto diagnostic criteria [31, 34, $41,64,65]$. One notable limitation was our inability to assess treatment received for PTSD and/or MDD throughout the study period. The Millennium Cohort Study did not include measures of treatment duration or type for either PTSD or MDD, so it was not possible to examine the effectiveness of treatment received, or how health care utilization might impact long-term comorbidity of PTSD and MDD. However, a study on PTSD symptom trajectories found that treatment received did not affect symptom class membership [51]. Future studies should be conducted to determine how treatment impacts trajectories of comorbid PTSD and MDD.

This study also has many notable strengths, including the large sample of service members and veterans with probable comorbid PTSD and MDD and our ability to examine trajectories of symptoms for both conditions over a duration of approximately 15 years. Furthermore, this study screened both individuals who may and may not seek treatment, which can help identify those at risk for chronic symptoms but might not receive necessary services. The Millennium Cohort Study includes service members and veterans from all service branches and components, which enhances the generalizability of study findings. Further, our broad assessment allows for examination of multiple factors that may be associated with worse prognosis for comorbid PTSD and MDD. Additionally, the current study followed participants during and after service, which is a notable strength, as Department of Defense studies typically only examine during-service outcomes and Department of Veterans Affairs studies usually only examine post-service outcomes.

\section{Conclusions}

Previous research indicates the comorbidity of PTSD/MDD is common and associated with worse sequelae compared to either condition alone. Results from this study indicate that comorbid PTSD and MDD symptoms move in concert with one another and, although many service members and veterans seem to rapidly recover from comorbid PTSD/ MDD symptoms, one-quarter of individuals reported high levels of both PTSD and MDD symptoms over time. Due to the high level of persistence and the tandem nature of these 2 conditions, it seems imperative that effective treatment is developed to address comorbid PTSD/MDD. Moreover, those with other mental disorders and physical conditions may have increased risk of chronic symptoms or slow recovery. Among those with comorbid PTSD/MDD, multidisciplinary or integrated medical care that targets both co-occurring mental and physical health conditions may be essential to help reduce symptoms of comorbid PTSD and MDD.

\section{Supplementary information}

Supplementary information accompanies this paper at https://doi.org/10. 1186/s12888-019-2375-1.



Abbreviations

DSM-IV-TR: Diagnostic and Statistical Manual of Mental Disorders, Fourth Edition, Text Revision; MDD: Major Depressive Disorder; PCL-C: PTSD 
Checklist-Civilian Version; PHQ: Patient Health Questionnaire; PTSD: Post Traumatic Stress Disorder; VIF: Variance Inflation Factors

\section{Acknowledgements}

In addition to the authors, the Millennium Cohort Study Team includes Lauren Bauer, MPH; Satbir Boparai, MBA; Ania Bukowinski, MPH; Carlos Carballo, MS; Dr. Felicia Carey; James Davies; Alex Esquivel, MPH; Gia Gumbs, MPH; Isabel Jacobson, MPH; Dr. Zeina Khodr; Claire Kolaja, MPH; William Lee; Gordon Lynch; Denise Lovec-Jenkins; Dr. Rayna Matsuno; Deanne Millard, BA; Dr. Chiping Nieh; Anet Petrosyan; Dr. Jacqueline Pflieger; Dr. Chris Phillips; Teresa Powell, MS; Dr. Sabrina Richardson; Anna Rivera, MPH; Beverly Sheppard; Steven Speigle; Evelyn Sun, MPH; Lexi Takata, BA; Dr. Daniel Trone; Daniel Vaughan; Jennifer Walstrom; Steven Warner, MPH; and Kelly Woodall, $\mathrm{MPH}$, from the Deployment Health Research Department, Naval Health Research Center, San Diego, California. The authors also thank the professionals from the US Army Medical Research and Materiel Command, especially those from the Military Operational Medicine Research Program, Fort Detrick, Maryland, Scott L. Seggerman from the Management Information Division, Defense Manpower Data Center, and the Millennium Cohort Study participants.

\section{Availability of data and materia}

The datasets analyzed during the current study are not publicly available due institutional regulations protecting service member survey responses but are available from the corresponding author on reasonable request (may require data use agreements to be developed).

\section{Authors' contributions}

RFA conceptualized the manuscript, helped conduct the statistical analysis, drafted the manuscript, and critically revised the manuscript based on feedback. TRG assisted with data analysis, wrote the methods sections, and provided critical review of the manuscript. KW and CAL helped conceptualize the manuscript, provided subject matter expertise, and critically revised and review the manuscript. BP assisted with data analysis, helped draft the manuscript, provided subject matter expertise, and critically revised and reviewed the manuscript. VS provided subject matter expertise and critically revised the manuscript. All authors read and approve the final manuscript.

\section{Funding}

The Millennium Cohort Study is funded through the Military Operational Medicine Research Program, United States Army Medical Research and Materiel Command (Fort Detrick, Maryland; work unit no. 60002). The funding body had no say in the design, conduct, data analysis, writing, or interpretation of the findings from this study.

\section{Ethics approval and consent to participate}

This study was approved by the Institutional Review Board at the Naval Health Research Center and all participants provided voluntary written informed consent.

\section{Consent for publication}

Not Applicable.

\section{Competing interests}

The authors declare that they have no competing interests. I am a military service member or employee of the U.S. Government. This work was prepared as part of my official duties. Title 17, U.S.C. \$105 provides that copyright protection under this title is not available for any work of the U.S. Government. Title 17, U.S.C. §101 defines a U.S. Government work as work prepared by a military service member or employee of the U.S. Government as part of that person's official duties. Report No. 19-40 was supported by the Military Operational Medicine Research Program under work unit no. 60002. The views expressed in this article are those of the authors and do not necessarily reflect the official policy or position of the Department of the Navy, Department of Defense, nor the U.S. Government. The study protocol was approved by the Naval Health Research Center Institutional Review Board in compliance with all applicable Federal regulations governing the protection of human subjects. Research data were derived from an approved Naval Health Research Center, Institutional Review Board protocol number NHRC.2000.0007.

\section{Author details}

${ }^{1}$ Department of Kinesiology, College of Education, Health, and Human Services, California State University, San Marcos, CA, USA. ${ }^{2}$ Leidos, 1195 Freedom Drive, Reston, VA 20190, USA. ${ }^{3}$ Deployment Health Research Department, Naval Health Research Center, San Diego, 140 Sylvester Road, San Diego, CA 92106-3521, USA. ${ }^{4}$ Health and Behavioral Sciences Department, Naval Health Research Center, San Diego, CA 92106-3521, USA.

Received: 26 May 2019 Accepted: 27 November 2019

Published online: 13 December 2019

\section{References}

1. Berntsen D, Johannessen KB, Thomsen YD, Bertelsen M, Hoyle RH, Rubin DC. Peace and war: trajectories of posttraumatic stress disorder symptoms before, during, and after military deployment in Afghanistan. Psychol Sci. 2012;23(12):1557-65

2. Koenen KC, Moffitt TE, Caspi A, Gregory A, Harrington H, Poulton RJ. The developmental mental-disorder histories of adults with posttraumatic stress disorder: A prospective longitudinal birth cohort study. J Abnorm Psychol. 2008;117(2):460.

3. Flory JD, Yehuda RJ. Comorbidity between post-traumatic stress disorder and major depressive disorder: alternative explanations and treatment considerations. Dialogues Clin Neurosci. 2015;17(2):141.

4. Walter KH, Levine JA, Highfill-McRoy RM, Navarro M, Thomsen CJ. Prevalence of posttraumatic stress disorder and psychological comorbidities among US active duty service members, 2006-2013. J Trauma Stress. 2018; 31(6):837-44.

5. Crum-Cianflone NF, Powell TM, LeardMann CA, Russell DW, Boyko EJ. Mental health and comorbidities in US military members. Mil Med. 2016; 181(6):537-45.

6. Rytwinski NK, Scur MD, Feeny NC, Youngstrom EA. The co-occurrence of major depressive disorder among individuals with posttraumatic stress disorder: a meta-analysis. J Trauma Stress. 2013;26(3):299-309.

7. Hepner KA, Sloss EM, Roth CP, Krull H, Paddock SM, Moen S, Timmer MJ, Pincus HA. Quality of care for PTSD and depression in the military health system: Phase I report. Rand health quarterly. 2016;6(1):4.

8. Tural Ü, Önder E, Aker TJ. Effect of depression on recovery from PTSD. Community Ment Health J. 2012;48(2):161-6.

9. Blanchard EB, Buckley TC, Hickling EJ, Taylor AE. Posttraumatic stress disorder and comorbid major depression: is the correlation an illusion? J Anxiety Disord. 1998;12(1):21-37.

10. Boscarino JA, Figley CR, Adams RE. Compassion fatigue following the September 11 terrorist attacks: A study of secondary trauma among New York City social workers. Int J Emerg Ment Health. 2004;6(2):57.

11. Campbell DG, Felker BL, Liu C-F, Yano EM, Kirchner JE, Chan D, Rubenstein LV, Chaney EF. Prevalence of depression-PTSD comorbidity: Implications for clinical practice guidelines and primary care-based interventions. J Gen Intern Med. 2007;22(6):711-8.

12. Chan $D$, Cheadle $A D$, Reiber $G$, Unützer J, Chaney EF. Health care utilization and its costs for depressed veterans with and without comorbid PTSD symptoms. Psychiatr Serv. 2009;60(12):1612-7.

13. Stapleton JA, Asmundson GJ, Woods M, Taylor S, Stein MB. Health care utilization by United Nations peacekeeping veterans with co-occurring, selfreported, post-traumatic stress disorder and depression symptoms versus those without. Mil Med. 2006;171(6):562-6.

14. Gonzalez OI, Novaco RW, Reger MA, Gahm GA. Anger intensification with combat-related PTSD and depression comorbidity. Psychol Trauma. 2016; 8(1):9.

15. Panagioti M, Gooding PA, Tarrier N. A meta-analysis of the association between posttraumatic stress disorder and suicidality: the role of comorbid depression. Compr Psychiatry. 2012;53(7):915-30.

16. Ramsawh HJ, Fullerton CS, Mash HBH, Ng THH, Kessler RC, Stein MB, Ursano RJ. Risk for suicidal behaviors associated with PTSD, depression, and their comorbidity in the US Army. J Affect Disord. 2014;161:116-22.

17. Armenta RF, Rush T, LeardMann CA, Millegan J, Cooper A, Hoge CW. Factors associated with persistent posttraumatic stress disorder among US military service members and veterans. BMC Psychiatry. 2018;18(1):48.

18. Galatzer-Levy IR, Huang SH, Bonanno GA. Trajectories of resilience and dysfunction following potential trauma: a review and statistical evaluation. Clin Psychol Rev. 2018;63:41-55. 
19. Donoho CJ, LeardMann C, O'malley CA, Walter KH, Riviere LA, Curry JF, Adler AB. Depression among military spouses: demographic, military, and service member psychological health risk factors. Depress Anxiety. 2018; 35(12):1137-44.

20. Porter B, Bonanno GA, Frasco MA, Dursa EK, Boyko EJ. Prospective posttraumatic stress disorder symptom trajectories in active duty and separated military personnel. J Psychiatr Res. 2017;89:55-64.

21. Bonanno GA, Mancini AD, Horton JL, Powell TM, LeardMann CA, Boyko EJ, Wells TS, Hooper TI, Gackstetter GD, Smith TC. Trajectories of trauma symptoms and resilience in deployed US military service members: prospective cohort study. Br J Psychiatry. 2012;200(4):317-23.

22. Dekel S, Solomon Z, Horesh D, Ein-Dor T. Posttraumatic stress disorder and depressive symptoms: joined or independent sequelae of trauma? J Psychiatr Res. 2014:54:64-9.

23. de Roon-Cassini TA, Mancini AD, Rusch MD, Bonanno GA. Psychopathology and resilience following traumatic injury: a latent growth mixture model analysis. Rehabil Psychol. 2010;55(1):1.

24. Erickson DJ, Wolfe J, King DW, King LA, Sharkansky EJ. Posttraumatic stress disorder and depression symptomatology in a sample of Gulf War veterans: a prospective analysis. J Consult Clin Psychol. 2001;69(1):41.

25. Schindel-Allon I, Aderka IM, Shahar G, Stein M, Gilboa-Schechtman E. Longitudinal associations between post-traumatic distress and depressive symptoms following a traumatic event: a test of three models. Psychol Med. 2010;40(10):1669-78.

26. Gray GC, Chesbrough KB, Ryan MA, Amoroso P, Boyko EJ, Gackstetter GD, Hooper TI, Riddle JR. The millennium cohort study: a 21-year prospective cohort study of 140,000 military personnel. Mil Med. 2002;167(6):483-8

27. Ryan MA, Smith TC, Smith B, Amoroso P, Boyko EJ, Gray GC, Gackstetter GD, Riddle JR, Wells TS, Gumbs G, et al. Millennium cohort: enrollment begins a 21-year contribution to understanding the impact of military service. J Clin Epidemiol. 2007;60(2):181-91.

28. Smith TC. The US Department of defense millennium cohort study: caree span and beyond longitudinal follow-up. J Occup Environ Med. 2009;51(10): 1193-201.

29. Weathers F, Huska J, Keane T. The PTSD Checklist-Civilian Version (PCL-C). Available from FW Weathers. National Center for PTSD, Boston Veterans Affairs Medical Center. 1991;150:02130.

30. Diagnostic and Statistical Manual of Mental Disorders. Washington, DC: American Psychiatric Association; 2014.

31. Terhakopian A, Sinaii N, Engel CC, Schnurr PP, Hoge CW. Estimating population prevalence of posttraumatic stress disorder: an example using the PTSD checklist. J Trauma Stress. 2008;21(3):290-300.

32. Hoge CW. Neuropsychiatric illnesses in war veterans. In: FA KDL, Hauser SL, Longo DL, Jameson JL, Loscaizo J, editors. Harrisons textbook of medicine. 19th ed. New York: McGraw Hill; 2015.

33. Kroenke K, Strine TW, Spitzer RL, Williams JB, Berry JT, Mokdad AH. The PHQ 8 as a measure of current depression in the general population. J Affect Disord. 2009;114(1-3):163-73

34. Wells TS, Horton JL, LeardMann CA, Jacobson IG, Boyko EJ. A comparison of the PRIME-MD PHQ-9 and PHQ-8 in a large military prospective study, the millennium cohort study. J Affect Disord. 2013;148(1):77-83.

35. Sandweiss DA, Slymen DJ, Leardmann CA, Smith B, White MR, Boyko EJ, Hooper TI, Gackstetter GD, Amoroso PJ, Smith TC. Preinjury psychiatric status, injury severity, and postdeployment posttraumatic stress disorder. Arch Gen Psychiatry. 2011;68(5):496-504

36. LeardMann CA, Smith B, Ryan MA. Do adverse childhood experiences increase the risk of postdeployment posttraumatic stress disorder in US marines? BMC Public Health. 2010;10(1):437.

37. Wells TS, LeardMann CA, Fortuna SO, Smith B, Smith TC, Ryan MA, Boyko EJ, Blazer D, Team MCS. A prospective study of depression following combat deployment in support of the wars in Iraq and Afghanistan. Am J Public Health. 2010;100(1):90-9.

38. Millegan J, Wang L, LeardMann CA, Miletich D, Street AE. Sexual trauma and adverse health and occupational outcomes among men serving in the US military. J Trauma Stress. 2016;29(2):132-40.

39. Hamby SL, Finkelhor D, Ormrod RK, Turner HAJD, NH: crimes agains children research center: the juvenile victimization questionnaire (JVQ): administration and scoring manual. 2004.

40. Hobson CJ, Kamen J, Szostek J, Nethercut CM, Tiedmann JW, Wojnarowicz S. Stressful life events: a revision and update of the social readjustment rating scale. Int J Stress Manag. 1998;5(1):1-23.
41. Spitzer RL, Kroenke K, Williams JB. Validation and utility of a self-report version of PRIME-MD: the PHQ primary care study. JAMA. 1999;282(18): 1737-44.

42. Kazis LE, Miller DR, Skinner KM, Lee A, Ren XS, Clark JA, Rogers WH, Spiro A III, Selim A, Linzer M. Patient-reported measures of health: the Veterans Health Study. J Ambul Care Manage. 2004:27(1):70-83.

43. Kocalevent R-D, Hinz A, Brähler E. Standardization of a screening instrument (PHQ-15) for somatization syndromes in the general population. BMC Psychiatry. 2013;13(1):91.

44. Kroenke K, Spitzer RL, Williams JBW. The PHQ-15: validity of a new measure for evaluating the severity of somatic symptoms. Psychosom Med. 2002; 64(2):258-66.

45. Enders CK, Bandalos DL. The relative performance of full information maximum likelihood estimation for missing data in structural equation models. 2001:8(3):430-57.

46. Jung T, Wickrama KJS, compass pp: An introduction to latent class growth analysis and growth mixture modeling. Soc Pers Pyschol Compass 2008, 2(1):302-317.

47. Nylund KL, Asparouhov T, Muthén BO. Deciding on the number of classes in latent class analysis and growth mixture modeling: A Monte Carlo simulation study. 2007;14(4):535-69.

48. Bonanno GA. Loss, trauma, and human resilience: Have we underestimated the human capacity to thrive after extremely aversive events? Am Psychol. 2004;59(1):20.

49. Solomon Z, Horesh D, Ein-Dor T, Ohry A. Predictors of PTSD trajectories following captivity: A 35-year longitudinal study. Psychiatry Res. 2012;199(3):188-94.

50. Donoho CJ, Bonanno GA, Porter B, Kearney L, Powell TM. A decade of war: prospective trajectories of posttraumatic stress disorder symptoms among deployed US military personnel and the influence of combat exposure. Am J Epidemiol. 2017;186(12):1310-8.

51. Galatzer-Levy IR, Ankri Y, Freedman S, Israeli-Shalev Y, Roitman P, Gilad M, Shalev AY. Correction: Early PTSD Symptom Trajectories: Persistence, Recovery, and Response to Treatment: Results from the Jerusalem Trauma Outreach and Prevention Study (J-TOPS). PLoS One. 2013;8(8):e70084.

52. Osenbach JE, Lewis C, Rosenfeld B, Russo J, Ingraham LM, Peterson R, Wang J, Zatzick DF. Exploring the longitudinal trajectories of posttraumatic stress disorder in injured trauma survivors. Psychiatry. 2014;77(4):386-97.

53. Flory JD, Yehuda R. Comorbidity between post-traumatic stress disorder and major depressive disorder: alternative explanations and treatment considerations. Dialogues Clin Neurosci. 2015;17(2):141.

54. Libretto S, Hilton L, Gordon S, Zhang W, Wesch J. Effects of integrative PTSD treatment in a military health setting. Energy Psychol. 2015;7(2):33-44.

55. LeardMann CA, Smith TC, Smith B, Wells TS, Ryan MA. Baseline self reported functional health and vulnerability to post-traumatic stress disorder after combat deployment: prospective US military cohort study. BMJ. 2009;338: b1273.

56. Outcalt SD, Kroenke K, Krebs EE, Chumbler NR, Wu J, Yu Z, Bair MJ. Chronic pain and comorbid mental health conditions: independent associations of posttraumatic stress disorder and depression with pain, disability, and quality of life. J Behav Med. 2015;38(3):535-43.

57. Nelson C, Cyr KS, Corbett B, Hurley E, Gifford S, Elhai JD, Richardson JD. Predictors of posttraumatic stress disorder, depression, and suicidal ideation among Canadian Forces personnel in a National Canadian Military Health Survey. J Psychiatr Res. 2011;45(11):1483-8.

58. Pietrzak RH, Johnson DC, Goldstein MB, Malley JC, Rivers AJ, Morgan CA Southwick SM. Psychosocial buffers of traumatic stress, depressive symptoms, and psychosocial difficulties in veterans of Operations Enduring Freedom and Iraqi Freedom: the role of resilience, unit support, and postdeployment social support. J Affect Disord. 2010;120(1-3):188-92.

59. Smith TC, Ryan MAK, Wingard DL, Slymen DJ, Sallis JF, Kritz-Silverstein D, Millennium cohort study T. New onset and persistent symptoms of posttraumatic stress disorder self reported after deployment and combat exposures: prospective population based US military cohort study. Br Med J. 2008;336(7640):366-71.

60. Wells TS, LeardMann CA, Fortuna SO, Smith B, Smith TC, Ryan MA, Boyko EJ, Blazer D, Millennium Cohort Study Team A prospective study of depression following combat deployment in support of the wars in Iraq and Afghanistan. Am J Public Health 2010, 100(1):90-99.

61. Cabrera OA, Hoge CW, Bliese PD, Castro CA, Messer SC. Childhood adversity and combat as predictors of depression and post-traumatic stress in deployed troops. Am J Prev Med. 2007;33(2):77-82. 
62. Smith B, Wingard DL, Ryan MA, Macera CA, Patterson TL, Slymen DJ. U.S military deployment during 2001-2006: Comparison of subjective and objective data sources in a large prospective health study. Ann Epidemiol. 2007:17(12):976-82.

63. Wells TS, Jacobson IG, Smith TC, Spooner CN, Smith B, Reed RJ, Amoroso PJ, Ryan MA. Prior health care utilization as a potential determinant of enrollment in a 21-year prospective study, the millennium cohort study. Eur J Epidemiol. 2008;23(2):79-87.

64. Smith TC, Smith B, Jacobson IG, Corbeil TE, Ryan MA. Reliability of standard health assessment instruments in a large, population-based cohort study. Ann Epidemiol. 2007;17(7):525-32.

65. Karstoft K-I, Andersen SB, Bertelsen M, Madsen T. Diagnostic accuracy of the posttraumatic stress disorder checklist-civilian version in a representative military sample. Psychol Assess. 2014;26(1):321.

\section{Publisher's Note}

Springer Nature remains neutral with regard to jurisdictional claims in published maps and institutional affiliations.

Ready to submit your research? Choose BMC and benefit from:

- fast, convenient online submission

- thorough peer review by experienced researchers in your field

- rapid publication on acceptance

- support for research data, including large and complex data types

- gold Open Access which fosters wider collaboration and increased citations

- maximum visibility for your research: over $100 \mathrm{M}$ website views per year

At BMC, research is always in progress.

Learn more biomedcentral.com/submissions 